\title{
Die Kunst des Sterbens
}

\author{
Erhard Taverna
}

Die Kamera folgt dem Highway durch die Wüste, biegt auf einen Feldweg ab und endet bei einem Bungalow, umgeben von Kakteen. Durch die Fenster der Veranda geht die Sicht auf Stapel von Büchern und Gegenständen, die einen Liegestuhl von allen Seiten eng umschliessen. Dort liegt eine alte, halbseitig gelähmte Frau, die seit Jahren auf ihren Tod wartet.

Die Kolonne vor der Kinokasse verrät, dass Elisabeth Kübler-Ross trotz jahrelangen Schweigens immer noch vielen Menschen ein Begriff ist. Mit ihrem Buch «On death and dying», 1969 über eine Million Mal verkauft und in 26 Sprachen übersetzt, wurde die bisher unbekannte Zürcher Ärztin für viele Jahre zum weltweit bekannten Star, als Frau des Jahres gefeiert, aber auch beneidet und angefeindet. «Sie war zur richtigen Zeit am richtigen Ort», erzählt eine ehemalige Mitarbeiterin aus der Psychiatrieklinik von Chicago, die erlebt hatte, wie die junge Ärztin sich für Sterbende interessierte und als Assistenz-Professorin Seminare für Pflegende und Studenten der Medizin und Theologie organisierte. Nicht zur Freude des medizinischen Kaders und der Spitalleitung, die ihrer Arbeit mangelnde Wissenschaftlichkeit vorwarfen und den Anstellungsvertrag nicht mehr verlängerten. Über die Verarbeitung von Trauer und Tod von Kindern, Jugendlichen und Erwachsenen waren schon seit Jahren Untersuchungen an verschiedenen Spitälern, auch in der Schweiz, durchgeführt worden. Doch erstmals wurden Resultate in einer für Laien verständlichen Sprache publik gemacht, in der die Betroffenen direkt zu Wort kamen, und die Identifikation mit einer charismatischen Person, ausserhalb der akademischen Zunft, mag die begeisterte Aufnahme zusätzlich gefördert haben.

Der Regisseur Stefan Haupt verwebt Archivmaterial, Zeugenaussagen und Interviews mit den Kübler-Drillingsschwestern zum eindrücklichen Portrait einer vielschichtigen Frauenbiographie. Die drei kamen in Zürich zur Welt, wobei die erstgeborene Elisabeth schon früh einen starken, rebellischen Willen bewies. Nach freiwilligen Arbeitseinsätzen im kriegsversehrten Frankreich und Polen machte sie gegen den Willen der Eltern die Abendmatura und studierte Medizin. Sie zog mit ihrem amerikanischen Ehe- mann nach New York, wo sie erstmals erlebte, wie in grossen Kliniken Schwerkranke, denen nicht mehr zu helfen war, emotional vernachlässigt wurden. «Sie (die institutionalisierten Routinen der Krankenhäuser) sind gefühlsarm und tragen viel zur Vereinsamung der Sterbenden bei», beobachtete damals der Philosoph Norbert Elias in seiner Abhandlung «Über die Einsamkeit der Sterbenden» und folgerte: «Was Menschen tun können, um Menschen ein leichtes und friedliches Sterben $\mathrm{zu}$ ermöglichen, bleibt noch herauszufinden.»

Genau dies herauszufinden war das lebenslängliche Ziel von Elisabeth Kübler-Ross, die in mehreren Büchern ihre Begegnungen mit sterbenden Erwachsenen und später auch mit Kindern beschrieben hat. Sie hat diesen Prozess mit den zu durchlaufenden Phasen von Nichtwahrhabenwollen - Zorn - Verhandeln - Depression und Zustimmung auf eine gängige Formel gebracht.

Der vom Bundesamt für Kultur, von Stadt und Kanton Zürich, den Landeskirchen und weiteren Gemeinden unterstützte Film erzählt die Geschichte einer überzeugten Einzelgängerin, die wesentlich dazu beigetragen hat, ein verdrängtes Thema den Kollegen und Seelsorgern, aber auch den Angehörigen und der ganzen Gesellschaft wieder bewusstzumachen. Die Psychiaterin hat im Laufe ihrer steilen Karriere alle Vorteile und Nachteile ihres missionarischen Alleinganges zu spüren bekommen. Geehrt mit Auszeichnungen, Titeln und Einladungen war sie nicht immer gefeit vor den Versuchungen des Starrummels, vor esoterischen Irrwegen und vor Intoleranz gegenüber Andersdenkenden. An ihrem fast besessenen Arbeitseifer scheiterte die Familie mit Ehemann, Tochter und Sohn. Ihre Neugier, die Schwelle nach dem Tod zu erkunden, führte sie zeitweise in die Fänge von Scharlatanen und Sektierern; ihre oft barsche und ungeduldige Art mit Gesunden zerstörte das zweite grosse Unternehmen eines erfolgreichen Farmbetriebes mit Kongresszentrum in den waldigen Hügeln Virginias. Von der Brandstiftung, die mit dem Wohnhaus auch Archiv und Bibliothek zerstörte, hat sie sich nie mehr erholt. Einer Reihe von kleineren Hirnschlägen folgte die bleibende Lähmung vor acht Jahren. 
Die inzwischen verstorbene Schwester Erika ist im Film die liebevolle Kronzeugin für das Leben der erfolgreichen Schwester, das sie humorvoll und kritisch kommentiert.

Doch die vom Erfolg Verlassene ist eine Kämpferin geblieben. Witzig-sarkastisch und frei von Selbstmitleid beschreibt sie ihren heutigen Zustand, spricht von den spirituellen Aufgaben, die ihr noch verblieben sind, und wünscht sich im Jenseits, Gandhi und Jung zu begegnen: «Ich werde durch die Galaxien tanzen, darauf freue ich mich.»

«Dem Tod ins Gesicht sehen». Buch und Regie: Stefan Haupt. Produktion: Fontana Film Zürich. 